\title{
Data Resource Profile: The Korea National Hospital Discharge In-depth Injury Survey (KNHDIS)
}

\author{
Yeon-Kyeng Lee: 0000-0002-0828-455x \\ Sung Ok Hong: 0000-0002-0787-4267 \\ Su-Jung Park: 0000-0002-4616-4612 \\ Mijin Park: 0000-0002-3871-0468 \\ Kyunghae Wang: 0000-0002-4239-8294 \\ Mini Jo: 0000-0002-5965-1014 \\ Jeongah Oh: 0000-0002-9675-2818 \\ Sin Ae Lee: 0000-0001-7943-4642 \\ Hyeon Ju Lee: 0000-0003-1341-8513 \\ Jungeun Oh: 0000-0002-0222-1208 \\ Dosang Lim: 0000-0003-1897-149X \\ Sanghui Kweon: 0000-0002-2678-8858 \\ Youngtaek Kim: 0000-0003-0139-7620
}

Yeon-Kyeng Lee ${ }^{1}$, Sung Ok Hong ${ }^{1}$, Su-Jung Park ${ }^{1}$, Mijin Park ${ }^{1}$, Kyunghae Wang $^{1}$, Mini Jo ${ }^{1}$, Jeongah $\mathrm{Oh}^{1}$, Sin Ae Lee ${ }^{1}$, Hyeon Ju Lee ${ }^{1}$, Jungeun $\mathrm{Oh}^{1}$, Dosang Lim ${ }^{1}$, Sanghui Kweon ${ }^{1}$, Youngtaek Kim ${ }^{2}$

${ }^{1}$ Korea Diseases Control and Prevention Agency, Cheongju, Korea

${ }^{2}$ Public Health \& Medical Service Office, Chungnam National University Hospital, Daejeon, Korea

Conceptualization: Y Lee, S Hong, and Y Kim; Data curation: S Hong, Y Lee and S Kweon; Formal analysis: M Park and D Lim; Investigation: M Park, K Wang, M Jo, J Ah, S Ae, H Lee, and J Oh; Methodology: S Hong, Y Lee and Y Kim; Data validation: S Park, Y Lee and S Kweon; Writing-original draft: Y Lee; Writing-review \& editing: all authors.

*Corresponding author

- Name: Youngtaek Kim

- Position: Professor

- Degree: M.D., PhD.,

- Address: 282 Munhwa-ro, Jung-gu, Daejeon, 35015, Korea

- Telephone: +82-42-338-2000 mobile 010-9099-9036

- Fax: +82-42-338-2001

- E-mail: usconway@gmail.com 


\section{Data Resource Profile: The Korea National Hospital Discharge In-depth Injury Survey (KNHDIS)}

\section{Introduction}

Injuries constitute a major public health problem, killing more than 5 million people ( $9 \%$ of deaths) worldwide each year and causing many more cases of disability. In Korea, the death rate from injuries has dropped from 61.2 per100 000 in 2009 to 56.5 in 2019, with traffic accidents accounting for approximately $10 \%$ of deaths in aged 1- 29 group in 2019[1]. Injuries, both unintentional and intentional injuries are viewed as largely preventable events. Furthermore, injuries and their burden can be reduced with effective measures of prevention and treatment[2].

The WHO has suggested injury surveillance system to inform about injury prevention and treatment, and to improve recovery outcomes in 2001. Many countries such as the US, Canada, Australia, China applied the WHO's injury surveillance guidelines to assess the pattern and trend of injuries[3]. In 2005, the KDCA launched an injury surveillance system called the Korea National Hospital Discharge In-depth Injury Survey (KNHDIS) with hospital based data, patients' demographic data (age, sex, and geographic area), details on injury (intent, place, mechanism, nature of injury), and contextual data (date of admission and discharge, outcomes, payment information) in order to understand the scale of injuries, identify risk factors, and provide data supporting prevention policies and intervention strategies suggested by the WHO injury surveillance guidelines. It is an integrated system of data collection, analysis, interpretation and communication. In addition, the KNHDIS is a national probability survey and has been conducted annually since its inception.

The KNHDIS defines patients with injury-related discharges as S00-T98 (injury, poisoning and a few other consequences of external causes) of the International Classification of Diseases, Tenth Revision (ICD-10) [4], which was designated in addition to the main diagnosis or sub-diagnosis code.

\section{Data resource area and population coverage}

The KNHDIS is an ongoing probability survey and targets injured patients admitted to hospitals. The scope of the KNHDIS encompasses patients discharged from all acute general hospitals of 100 or more beds, except certain types including single specialized hospitals, nursing hospitals, geriatric hospitals, veterans' hospitals, military hospitals, and rehabilitation hospitals. In addition, cases of 
patients who have only stayed in the emergency room, as well as those who had normal full-term spontaneous delivery were excluded[5]. The KNHDIS data captured multiple admissions with no distinction between the initial admission and the subsequent readmissions, except in the first surveyed year which excluded multiple events.

\section{Data Collection Procedures}

Two data collection procedures are used for the KNHDIS. One is an automated system in which the sampled hospitals extract the Korea Uniform Hospital Discharge DataSet (KUHDDS), gather data from forms with information about the injury, and then transmit the data electronically to the data system operated by the KDCA, known as the integrated disease health management system (the IS, www.is.kdca.go.kr) [6].

The procedure that hospitals with the automated system go through involves the Electronic Medical Record (EMR) system automatically extracting the KUHDDS, followed by the hospital's staff surveying for the KUHDDS and the injury-related codes.

The other is a manual system in which sample selection and transcription of information from the hospital records to abstract forms on the IS are performed by trained research staffs of the KDCA.

Approximately $68.6 \%$ of the sampled hospitals provide their data through the automated system; and those hospitals accounted for $89.0 \%$ of the total data in 2018. The survey participation rate of sampled hospitals tended to slightly decrease over time-from $98.0 \%$ in 2004 to $95.5 \%$ in 2018 (as of 2019, Table 1)[7].

\section{Sampling Design}

The original sample was selected in 2005 from a pool of general hospitals listed in the national patient survey. A two-stage stratified cluster sampling scheme was applied, and hospitals were stratified into four strata based on the number of beds (100-299, 300-499, 500-999, and over 1000 beds) and on their geographic locations (provinces referred to as "Si", "Do"). However, 16 regional emergency medical centers, four specialized emergency medical centers, and five specialized burn care hospitals were mandatorily selected from 2007[8]. In the first stage of the scheme, individual hospitals were selected as the primary sampling unit (PSU); and in the second stage, discharged cases from the sampled hospitals were selected as the secondary sampling unit (SSU). The sample plan has had updated the selection probabilities periodically based on previous survey results and the variance in

63 the number of hospitals. The sample size was 150 hospitals in the first surveyed year, and was 
expanded to 200 hospitals by 2017[9]. The selected discharge cases were approximately $9 \%$ of the total discharge cases (approximately 10\% until 2006), but did not exceed 6,000 cases per hospital. The selection process was done using the systematic sampling method. The number of cases selected for hospitals with uncomputerized KUHDDS was based on the number of beds as follows: a maximum of 300 cases for 100-199 beds, 420 cases for 200-299 beds, and 540 cases for hospitals with more than 300 beds. In regard to the 2010 survey population, the probability was doubled for children of ages 0 to 4 and for women of ages 25 to 35 due to high estimation errors in the previous survey results. Furthermore, the sample size will be increased to up to 250 hospitals in order to better estimate the representative statistics of each region.

The KNHDIS data captured multiple admissions with no distinction between the initial admission and the subsequent readmissions, except in the first surveyed year which excluded multiple events. Injury cases were account for approximately $13 \%-15 \%$ of total discharges, including multiple events every year. In 2018, 302,593 hospitalizations were reviewed, from which 38,109 injury cases were identified and examined (Table 2).

\section{Estimation of Total Discharged Cases}

80 The survey was a complex sample survey, and appropriate weights were applied for the estimation. 81 The number of injury cases was estimated using the estimation of the mid-year population of each 82 year. Linear variance estimation was carried out using the Taylor series, with the selected procedure being SURVEYMEANS provided by SAS, using the latest version available for that report year (e.g. ver 9.4 in 2019) (SAS Institute Inc., Cary, NC, USA).

The weighting was calculated by multiplying the probability of the hospital selection (PSU) by the probability of the patient selection (SSU). The formula for estimating the total $(Y)$ is defined as follows:

$\hat{Y}=\sum_{h=1}^{H} \frac{N_{h}}{n_{h}} \sum_{i=1}^{n_{h}} \frac{M_{h i}}{m_{h i}} \sum_{j=1}^{m_{h i}} y_{h i j}=\sum_{h=1}^{H} \sum_{i=1}^{n_{h}} \sum_{j=1}^{m_{h i}} w_{h i j} \cdot y_{h i j}$

where,

89 h: stratum h by hospital size $(\mathrm{h}=1,2, \mathrm{H}=4)$

$90 \quad i: i^{\text {th }}$ hospital in stratum $h, i=1,2, \ldots, n_{h}$

$91 \mathrm{j}: j^{\text {th }}$ patient of $i^{\text {th }}$ hospital in stratum $h, j=1,2, \ldots m_{h i}$

$92 N_{h}$ is the number of target hospitals in stratum $h$.

$93 \underline{n}_{h}$ is the number of hospitals to be sampled in stratum $h$.

$94 \quad \mathbf{M}_{h i}$ is total number of discharged patients of $i^{\text {th }}$ hospital in stratum $h$.

$95 m_{h i}$ is the number of sampled discharged patients in the $i^{\text {th }}$ hospital in stratum $h$. 
$W_{h i j}$ is the weighting of discharged patients to be sampled in hospital $j$ of stratum $h$.

$$
w_{h i j}=\frac{N_{h}}{n_{h}} \times \frac{M_{h i}}{m_{h i}}
$$

97 The variance of the estimated total number of discharged patients $Y$ is computed using the following formula: $\hat{V}(\hat{Y})=\sum_{h=1}^{H} \hat{V}_{h}(\hat{Y})$

where, $\hat{V}_{h}(\hat{Y})=\frac{n_{h}}{n_{h}-1} \sum_{i=1}^{n_{h}}\left(y_{h i \cdot}-y_{h . .}\right)^{2}, y_{h i}=\sum_{j=1}^{m_{h i}} w_{h i j} \cdot y_{h i j}, y_{h \cdot .}=\left(\sum_{i=1}^{n_{h}} y_{h i}\right) / n_{h}$

The standard error is computed as the square root of the total variance, $\sqrt{\hat{V}(\hat{Y})}$.

\section{Data Validation and Quality}

103 The KCDC developed a quality management program, which involves first checking the data transmitted into the IS. Data are subject to automatic quality control checks on submission the original entry. Various errors - including omission of essential items, duplicate transmissions of the same data, as well as errors in admission and discharge dates, code values for each item, the dates of the main operations, and the date of the injury occurrence-were analyzed and returned. The second step is to verify the items surveyed by the specialized quality control team within the KCDC and identify any logical errors that may exist between the said items (the relationship between the patient's age and the source of medical expenses, between the external code of injury and the information gathered from

111 the in-depth survey, between age and the location and activity leading to the injury, between age and

112 the diagnosis and the surgical code, between diagnoses relating to only one of the either genders and 113 the surgical code, etc.). Third, external experts review the cases of patients who were hospitalized for more than 180 days, which are then excluded from the national statistic. However, information that is related to disease and treatment, such as codes for diagnoses, procedures, and for the accuracy of the original cause for injured patients as well as those of deceased neonatal patients, is provided as raw data. Any errors or information requiring reconfirmation were corrected with the hospital.

\section{Data Collected}

\section{Patient and Clinical Information}

121 The types of data collected include the hospitals' information; the patients' demographic information 122 including age, gender, residence zip code, primary payer/insurance status; detailed clinical 123 information and injury-related codes such as the mechanism and location of the occurrence of the injury based on the International Classification of External Causes of Injuries version 1.2[10], with 30 
variables available in the core dataset(see Table 3).

126 Primary diagnosis and additional diagnosis were coded based on the ICD-10. Procedures were coded 127 as ICD-10 and ICD-9CM. ICD-10 was used between 2005 and 2014 then the Korean Standard 128 Classification of Diseases-7th edition (KCD-7)[11] by the Statistics Korea was applied form 2015, 129 which is the Korean version of ICD-10 including Korea specific diseases code. Primary procedure 130 defined as surgical operation and additional procedures included endoscopic polypectomy, Gamma 131 knife, extracorporeal shock wave lithotripsy and special examination for diagnosis purpose. For each 132 discharges record, up to 20 additional diagnostic and additional procedure codes were collected from 133 the second KNHDIS. Apart from data on diagnoses and procedures, the survey contains information 134 on dates of admission, each coded procedure, discharge and injury occurred, primary payer/insurance 135 status such as national health insurance, medical care (Medicaid, Medicare), car insurance industrial 136 accident compensation insurance, or uninsured.

\section{Injury Information}

139 The injury-related contents were developed based on the International Classification of External 140 Causes of Injuries (ICECI) recommended by the World Health Organization. Key data elements on 141 injury include intent of injury, place of occurrence, injury mechanism and activities undertaken when 142 injured (sports, leisure activities, work, treatment, and education). The discharges with diagnosis 143 coded as S00-T75 and T79 required to collect information external causes of injuries (V-Y code), and 144 all 10 variables in injury information dataset (Table 3). The external causes of injury were collected 145 up to 2 codes to understand consequence after original injury. Injuries were classified by the intention 146 of act into 4 categories: unintentional injuries, intentional injuries, violence-related injuries, and legal 147 intervention. Place of injury occurred was coded linked with external cause of injury as residence, 148 school and school area, commercial facilities, farms, medical facilities, cultural facilities such as 149 amusement park, public building, industrial or construction place and etc. Injury mechanism provides 150 information about method or instrument that caused the injury. The outcome of injury patient at the 151 time of discharge was evaluated with medical record and coded with Glasgow Outcome Score of 5(1

152 for dead, 2 for persistent vegetative state, 3 for severe disability, 4 for moderate disability, and 5 for 153 good recovery).

154 The following were surveyed for as needed: the means of transportation (pedestrians, bicycles, 155 motorcycles, cars, buses, and airplanes), suicide risk factors (conflict with family members, disease, 156 financial problems, death in the family, and abuse), and toxic substances. For cases with T78, T80157 T98, and Y40-Y98, only external causes of injuries were surveyed (E, V code with the ICD-9, V, W, X 158 code with the ICD-10). The item "nature of injury" was surveyed separately until 2005, after which it 
159 was changed to be generated from the S00-T98 code of the primary diagnosis or additional diagnosis.

160 Each surveyed year estimated the injury discharge rates using the year estimate population by 161 demographic characteristics, intent, injury mechanism, and etc from 2004 to 2017 (Table 4).

\section{Data Resource Use}

164 The KNHDIS provides a unique data source not currently available elsewhere in Korea and has been 165 widely used by various academic researchers and policy makers. Annual reports have been published 166 in the late part of their subsequent years since 2006 (target data of 2004)[12]. The KNHDIS has 167 provided the health statistics that were needed for the development of injury prevention-related 168 objectives for the Health Plan 2020 (HP2020), which is the national comprehensive health plan put 169 together by the Korean Ministry of Health and Welfare(KMOHW)[13]. The provided indicators were 170 the rates of admission to hospitals for causes relating to intentional or unintentional injuries, traffic 171 accidents. In support of the Presidential agenda goals, the KNHDIS has also provided seven indicators relating to safety-related objectives for children under the age 14 since 2011[14]. These include rates of admission caused by intentional/unintentional injuries, poisoning, sports/recreation injuries, traffic accidents, and pedestrian traffic accidents. The data was also used to revise the Korea Classification of Diseases (KCD) by Statistics Korea[15]. With over 100 publications as of July 2020, the KNHDIS has been used to answer a variety of relevant research questions. The main research issues it addresses include the effect of disease burden[16-18] and risk factors on hospitalization duration[18-21], epidemiologic characteristic of injuries[22-25], and so on. A full list of publications involving the KNHDIS data in domestic and international journals is available from the supplementary data section at IJE online. The annual KNHDIS symposium provided KCDC have been held 14 times up to 2019, with approximately 250 researchers attending each time. The comprehensive injury fact sheets were published annually by collaborating with various agencies and KCDC since 2011, such as the fire

183 agency, the statistics agency, the Rural Development Administration, the National Medical Center, the

184 National Health Insurance Corporation, the Road Traffic Authority, and the School Safety and 185 Insurance Federation. Furthermore, the data has worked to increase awareness regarding the 186 importance of injury prevention, and a chapter about this has been placed in Korean language textbooks of the $4^{\text {th }}$ graders.

\section{Strengths and Weaknesses}

190 The KNHDIS is an ongoing survey that reflects Korea's national representative sample, is a valuable 191 source of understanding injury-related information, and improves policies made to prevent injuries. It 
192 has the advantage of being able to grasp the trend of injuries in a time-sequential manner, and it

193 continually produces systematic national health and medical statistics related to injuries for the public

194 and the academic sector.

195 The KNHDIS covers not only patients with health insurance provided by the Korea National Health

196 Insurance Service, but also those who are covered by other types of insurance, such as industrial

197 accident insurance and car insurance. Furthermore, the contents of the survey are coded with ICD-10

198 and ICECI that makes international comparisons possible.

199 The KNHDIS has several limitations. The KNHDIS only surveys hospitals with more than 100 beds,

200 and as such additional surveys on hospitals with less than 100 beds are needed, as well as ones on

201 outpatient injuries. Also, the dataset cannot distinguish cases of readmission to multiple hospitals

202 because it does not collect personal linkable identification codes. In other words, all the data

203 surrounding one particular discharge case are from one hospital.

204

\section{Data Resources Access}

206 Data are available for all the years the survey was conducted. The annual reports are downloadable at 207 the KDCA website (http://www.kdca.go.kr) and the Korea Statistics website (http://mdis.kostat.go.kr).

208 A micro data is available as request by email (kcdcinjury@korea.kr) with an application 209 (https://www.kdca.go.kr/board/board.es?mid=a20507030000\&bid=0020). Qualified applicants are 210 able to submit an application form summarizing the proposed research project that will be using the 211 KNHDIS. For successful applicants, data will be transferred by the KCDC injury data team. Further 212 information and enquires can be submitted to kcdcinjury@korea.kr.

\section{Acknowledgements}

215 We are grateful to all participants of the KNHDIS. We also appreciate the contributions of our staff 216 members, including the medical record review staffs, the Korean Medical Record Association, and the 217 expert committees that have provided technical support to the KNHDIS.

218

219 Conflict of interest: None declared.

220 
221 Table 1. The number of sampled hospitals, their rates of participation, and number of surveyed cases in the 222 KNHDIS

\begin{tabular}{|c|c|c|c|c|c|c|c|c|c|c|c|c|c|c|c|}
\hline \multirow{2}{*}{$\begin{array}{c}\text { Target } \\
\text { year }\end{array}$} & \multicolumn{5}{|c|}{ Number of Target population hospitals } & \multicolumn{5}{|c|}{ Number of Sample hospitals (A) } & \multicolumn{5}{|c|}{$\begin{array}{l}\text { Number of Participated hospitals (B) } \\
\text { (A/B, \%) }\end{array}$} \\
\hline & sum & $\begin{array}{l}100- \\
299\end{array}$ & $\begin{array}{l}300- \\
499\end{array}$ & $\begin{array}{l}500- \\
999\end{array}$ & $\geq 1000$ & sum & $\begin{array}{l}100- \\
299\end{array}$ & $\begin{array}{l}300- \\
499\end{array}$ & $\begin{array}{l}500- \\
999\end{array}$ & $\geq 1000$ & Sum & $\begin{array}{l}100- \\
299\end{array}$ & $\begin{array}{l}300- \\
499\end{array}$ & $\begin{array}{l}500- \\
999\end{array}$ & $\geq 1000$ \\
\hline 2004 & 512 & 334 & 84 & 84 & 10 & 150 & 70 & 27 & 43 & 10 & $\begin{array}{c}147 \\
(98.0)\end{array}$ & $\begin{array}{c}67 \\
(95.7)\end{array}$ & $\begin{array}{c}27 \\
(100.0)\end{array}$ & $\begin{array}{c}43 \\
(100.0)\end{array}$ & $\begin{array}{c}10 \\
(100.0)\end{array}$ \\
\hline 2005 & 512 & 334 & 84 & 84 & 10 & 150 & 70 & 27 & 43 & 10 & $\begin{array}{c}147 \\
(98.0)\end{array}$ & $\begin{array}{c}68 \\
(97.1)\end{array}$ & $\begin{array}{c}27 \\
(100.0)\end{array}$ & $\begin{array}{c}42 \\
(97.7)\end{array}$ & $\begin{array}{c}10 \\
(100.0)\end{array}$ \\
\hline 2006 & 512 & 334 & 84 & 84 & 10 & 150 & 70 & 27 & 43 & 10 & $\begin{array}{c}144 \\
(96.0)\end{array}$ & $\begin{array}{c}65 \\
(92.9)\end{array}$ & $\begin{array}{c}26 \\
(96.3)\end{array}$ & $\begin{array}{c}43 \\
(100.0)\end{array}$ & $\begin{array}{c}10 \\
(100.0)\end{array}$ \\
\hline 2007 & 561 & 408 & 75 & 71 & 7 & 170 & 102 & 19 & 42 & 7 & $\begin{array}{c}165 \\
(97.1)\end{array}$ & $\begin{array}{c}100 \\
(98.0)\end{array}$ & $\begin{array}{c}18 \\
(94.7)\end{array}$ & $\begin{array}{c}40 \\
(95.2)\end{array}$ & $\begin{array}{c}7 \\
(100.0)\end{array}$ \\
\hline 2008 & 561 & 408 & 75 & 71 & 7 & 170 & 102 & 19 & 42 & 7 & $\begin{array}{c}170 \\
(100.0)\end{array}$ & $\begin{array}{c}102 \\
(100.0)\end{array}$ & $\begin{array}{c}19 \\
(100.0)\end{array}$ & $\begin{array}{c}42 \\
(100.0)\end{array}$ & $\begin{array}{c}7 \\
(100.0)\end{array}$ \\
\hline 2009 & 561 & 408 & 75 & 71 & 7 & 170 & 102 & 19 & 42 & 7 & $\begin{array}{c}170 \\
(100.0)\end{array}$ & $\begin{array}{c}102 \\
(100.0)\end{array}$ & $\begin{array}{c}19 \\
(100.0)\end{array}$ & $\begin{array}{c}42 \\
(100.0)\end{array}$ & $\begin{array}{c}7 \\
(100.0)\end{array}$ \\
\hline 2010 & 561 & 408 & 75 & 69 & 9 & 170 & 103 & 18 & 40 & 9 & $\begin{array}{c}166 \\
(97.6)\end{array}$ & $\begin{array}{c}101 \\
(98.1)\end{array}$ & $\begin{array}{c}18 \\
(100.0)\end{array}$ & $\begin{array}{c}39 \\
(97.5)\end{array}$ & $\begin{array}{c}8 \\
(88.9)\end{array}$ \\
\hline 2011 & 561 & 408 & 75 & 69 & 9 & 170 & 103 & 17 & 41 & 9 & $\begin{array}{c}166 \\
(97.6)\end{array}$ & $\begin{array}{c}101 \\
(98.1)\end{array}$ & $\begin{array}{c}17 \\
(100.0)\end{array}$ & $\begin{array}{c}41 \\
(100.0)\end{array}$ & $\begin{array}{c}7 \\
(77.8)\end{array}$ \\
\hline 2012 & 561 & 408 & 75 & 69 & 9 & 170 & 103 & 17 & 41 & 9 & $\begin{array}{c}166 \\
(97.6)\end{array}$ & $\begin{array}{c}101 \\
(98.1)\end{array}$ & $\begin{array}{c}17 \\
(100.0)\end{array}$ & $\begin{array}{c}40 \\
(97.6)\end{array}$ & $\begin{array}{c}8 \\
(88.9)\end{array}$ \\
\hline 2013 & 561 & 408 & 75 & 69 & 9 & 170 & 103 & 17 & 41 & 9 & $\begin{array}{c}164 \\
(96.5)\end{array}$ & $\begin{array}{c}99 \\
(96.1)\end{array}$ & $\begin{array}{c}17 \\
(100.0)\end{array}$ & $\begin{array}{c}41 \\
(100.0)\end{array}$ & $\begin{array}{c}7 \\
(77.8)\end{array}$ \\
\hline 2014 & 561 & 408 & 75 & 69 & 9 & 170 & 103 & 17 & 41 & 9 & $\begin{array}{c}164 \\
(96.5)\end{array}$ & $\begin{array}{c}98 \\
(95.1)\end{array}$ & $\begin{array}{c}17 \\
(100.0)\end{array}$ & $\begin{array}{c}41 \\
(100.0)\end{array}$ & $\begin{array}{c}8 \\
(88.9)\end{array}$ \\
\hline 2015 & 561 & 408 & 75 & 69 & 9 & 170 & 102 & & 41 & 9 & $\begin{array}{c}165 \\
(97.1)\end{array}$ & $\begin{array}{c}99 \\
(97.1)\end{array}$ & $\begin{array}{c}18 \\
(100.0)\end{array}$ & $\begin{array}{c}40 \\
(97.6)\end{array}$ & $\begin{array}{c}8 \\
(88.9)\end{array}$ \\
\hline 2016 & 561 & 408 & 75 & 69 & 9 & 170 & 101 & 18 & 42 & 9 & $\begin{array}{c}161 \\
(94.7)\end{array}$ & $\begin{array}{c}95 \\
(94.1)\end{array}$ & $\begin{array}{c}17 \\
(94.4)\end{array}$ & $\begin{array}{c}41 \\
(97.6)\end{array}$ & $\begin{array}{c}8 \\
(88.9)\end{array}$ \\
\hline 2017 & 572 & 414 & 64 & 77 & 17 & 200 & 95 & 31 & 57 & 17 & $\begin{array}{c}188 \\
(94.0)\end{array}$ & $\begin{array}{c}91 \\
(95.8)\end{array}$ & $\begin{array}{c}28 \\
(90.3)\end{array}$ & $\begin{array}{c}55 \\
(96.5)\end{array}$ & $\begin{array}{c}14 \\
(82.4)\end{array}$ \\
\hline 2018 & 572 & 414 & 64 & 77 & & 200 & 95 & 31 & 57 & 17 & $\begin{array}{c}191 \\
(95.5)\end{array}$ & $\begin{array}{c}91 \\
(95.8)\end{array}$ & $\begin{array}{c}30 \\
(96.8)\end{array}$ & $\begin{array}{c}55 \\
(96.5)\end{array}$ & $\begin{array}{c}15 \\
(88.2)\end{array}$ \\
\hline
\end{tabular}


Table 2. The KNHDIS databases between 2004 and 2008

\begin{tabular}{c|ccc}
\hline Target year & $\begin{array}{r}\text { No. of hospitals } \\
\text { participated }\end{array}$ & No. of discharged cases & No. of injury related cases \\
\hline 2004 & 147 & 175,100 & 26,791 \\
2005 & 147 & 161,997 & 24,818 \\
2006 & 144 & 170,008 & 25,511 \\
2007 & 169 & 179,094 & 27,291 \\
2008 & 170 & 190,074 & 28,031 \\
2009 & 170 & 198,586 & 29,030 \\
2010 & 166 & 220,838 & 31,654 \\
2011 & 166 & 225,105 & 31,425 \\
2012 & 167 & 235,526 & 32,758 \\
2013 & 163 & 214,605 & 30,589 \\
2014 & 165 & 224,061 & 31,389 \\
2015 & 165 & 227,615 & 31,784 \\
2016 & 162 & 235,579 & 30,829 \\
\hline & 188 & 291,786 & 37,752 \\
\hline
\end{tabular}


Table 3. The KNHDIS Data elements (as of Jun 2020)

\begin{tabular}{l|ll}
\hline Subjects & Items & Contents \\
\hline & Hospital information & $\cdot$ Hospital identification code \\
& & $\cdot$ Number of bed in hospital \\
& & $\cdot$ Hospital address
\end{tabular}

The KUHDDS

\begin{tabular}{|c|c|c|}
\hline & Demographics & $\begin{array}{l}\cdot \text { Gender } \\
\text { - Age at admission } \\
\text { - } \text { Date of birth } \\
\text { - Zip code }\end{array}$ \\
\hline & Admission information & $\begin{array}{l}\text { - Expected source of payments } \\
\text { - Admission date } \\
\text { - Discharge date } \\
\text { - Admission route (e.g. emergency, outpatient) }\end{array}$ \\
\hline & Medical information & $\begin{array}{l}\text { - Primary diagnosis KCD-10 } 10^{\text {th }}\left(\mathrm{KCD}-7^{\text {th }}\right) \text { code } \\
\text { - Additional diagnosis KCD-10 } 10^{\text {th }}\left(\mathrm{KCD}-7^{\text {th }}\right) \\
\left.\text { code (up to } 20^{1}\right) \\
\left.\text { - External cause of injury (up to } 2^{2}\right) \\
\text { - Primary procedure ICD-9-CM } \\
\text { - Date of procedure } \\
\left.\text { - Additional procedure code (up to } 20^{1}\right) \\
\text { - Discharge method } \\
\text { - Underlying cause of death } \\
\text { - Discharge disposition (e.g. home, other } \\
\text { health care facility, expired) } \\
\text { - Treatment result (e.g. improved, ceased) }\end{array}$ \\
\hline \multicolumn{3}{|l|}{ Injured patients } \\
\hline $\begin{array}{l}\text { S00-T75, T79 } \\
\text { (ICD-10) }\end{array}$ & Injury information & $\begin{array}{l}\text { - Intent } \\
\text { - Place of occurrence } \\
\text { - Activity when injured } \\
\text { - Mechanism of injury } \\
\text { - Date of injury occurrence } \\
\text { - Nature of injury (e.g. superficial injury, open } \\
\text { wound, fracture; generated from ICD code T00- } \\
\text { 07, T20-632) } \\
\text { - Mode of transport } \\
\text { - Proximal Risk factors for intentional self- } \\
\text { harm (e.g. conflict with families, physical } \\
\text { illness, financial problem) } \\
\text { - Poisonous substance } \\
\text { - Glasgow Outcome Scale } \\
\text { - External causes of injuries (V-Y code) }\end{array}$ \\
\hline $\begin{array}{l}\text { T78, T80-T98, Y40- } \\
\text { Y98(ICD-10) }\end{array}$ & Injury information & - External causes of injuries (V-Y code) \\
\hline
\end{tabular}


Table 4. Estimated injury discharge rates ${ }^{*}, 2004-2017$

\begin{tabular}{|c|c|c|c|c|c|c|c|c|c|c|c|c|c|c|}
\hline & 2004 & 2005 & 2006 & 2007 & 2008 & 2009 & 2010 & 2011 & 2012 & 2013 & 2014 & 2015 & 2016 & 2017 \\
\hline Total & 9,081 & 9,477 & 9,490 & 10,091 & 10,518 & 11,131 & 11,979 & 12,488 & 13,093 & 13,184 & 13,505 & 13,800 & 14,218 & 14,199 \\
\hline Non-injuries & 7,722 & 8,007 & 7,995 & 8,551 & 8,891 & 9,464 & 10,136 & 10,663 & 11,164 & 11,222 & 11,499 & 11,732 & 12,162 & 12,042 \\
\hline Injuries & 1,359 & 1,470 & 1,495 & 1,541 & 1,628 & 1,667 & 1,843 & 1,825 & 1,929 & 1,962 & 2,006 & 2,068 & 2,056 & 2,157 \\
\hline Intent & 1,627 & 1,713 & 1,575 & 1,787 & 1,837 & 1,872 & 2,057 & 2,019 & 2,119 & 2,118 & 2,121 & 2,169 & 2,087 & 2,160 \\
\hline Non-intentional & 1,505 & 159 & 1,622 & 1,669 & 1,721 & 1,762 & 1,947 & 1,913 & 2,021 & 2,006 & 2,015 & 2,070 & 2,007 & 2,082 \\
\hline Intentional & 111 & 113 & 115 & 105 & 111 & 106 & 105 & 101 & 91 & 92 & 90 & 82 & 74 & 71 \\
\hline Unknown & 10 & 10 & 15 & 12 & 3 & 4 & 5 & 5 & 6 & 20 & 16 & 17 & 6 & 5 \\
\hline \multicolumn{15}{|l|}{ Age group } \\
\hline $0-14$ & 880 & 868 & 835 & 862 & 912 & 872 & 918 & 918 & 963 & 921 & 964 & 901 & 804 & 795 \\
\hline $15-24$ & 1,373 & 1,468 & 1,495 & 1,574 & 1,560 & 1,573 & 1,655 & 1,634 & 1,697 & 1,608 & 1,672 & 1,747 & 1,623 & 1,567 \\
\hline $25-34$ & 1,620 & 1,697 & 1,741 & 1,833 & 1,863 & 1,844 & 1,959 & 1,929 & 1,911 & 1,836 & 1,811 & 1,745 & 1,656 & 1,639 \\
\hline $35-44$ & 1,824 & 1,875 & 1,970 & 1,900 & 1,880 & 1,939 & 2,004 & 1,903 & 1,938 & 1,947 & 1,805 & 1,817 & 1,743 & 1,685 \\
\hline $45-54$ & 2,111 & 2,280 & 2,315 & 2,335 & 2,333 & 2,463 & 2,648 & 2,588 & 2,626 & 2,632 & 2,525 & 2,564 & 2,313 & 2,326 \\
\hline $55-64$ & 2,570 & 2,705 & 2,666 & 2,643 & 2,613 & 2,755 & 2,904 & 2,894 & 3,083 & 3,070 & 3,044 & 3,137 & 3,064 & 3,263 \\
\hline $65-74$ & 3,072 & 3,174 & 34,378 & 3,201 & 3,434 & 3,446 & 3,967 & 3,686 & 3,941 & 3,941 & 4,000 & 3,830 & 3,896 & 4,094 \\
\hline $75+$ & 3,958 & 4,188 & 4,451 & 4,226 & 4,641 & 4,481 & 5,242 & 5,057 & 5,644 & 5,485 & 5,786 & 6,101 & 6,272 & 6,666 \\
\hline \multicolumn{15}{|l|}{ Injury mechanism } \\
\hline Traffic accident & 669 & 690 & 714 & 746 & 743 & 745 & 772 & 734 & 771 & 729 & 731 & 738 & 670 & 660 \\
\hline Fall & 463 & 491 & 518 & 504 & 532 & 558 & 654 & 668 & 703 & 748 & 736 & 783 & 792 & 873 \\
\hline Stuck by/against & 164 & 173 & 246 & 243 & 242 & 239 & 268 & 263 & 274 & 248 & 251 & 252 & 231 & 256 \\
\hline Stabbing & 86 & 141 & 87 & 72 & 77 & 68 & 74 & 67 & 69 & 75 & 62 & 68 & 77 & 81 \\
\hline Poisoning & 47 & 47 & 61 & 52 & 55 & 58 & 58 & 55 & 57 & 57 & 59 & 53 & 50 & 45 \\
\hline Fire/Flame $^{1}$ & 35 & 323 & 35 & 46 & 54 & 61 & 59 & 52 & 56 & 56 & 67 & 58 & 51 & 31 \\
\hline Others & 163 & 152 & 90 & 124 & 134 & 143 & 172 & 180 & 189 & 205 & 215 & 217 & 216 & 214 \\
\hline
\end{tabular}

* Discharge rate: discharge rate per 100,000 population applied population estimate of the surveyed year. 


\section{Reference}

242 1. Statistics Korea, Death rate cause by injury. 2021 [cited $202112 \mathrm{Mar}$ ].

243 2. PJ, G., Global burden of injuries: it is time to understand the data in order to intervene. Injury Prevention, 244 2020. 26(Garcia PJ Global burden of injuries: it is time to understand the data in order to intervene Injury 245 Prevention 2020;26:i1-i2.): p. 2.

246 3. Mirani, N., H. Ayatollahi, and D. Khorasani-Zavareh, Injury surveillance information system: A review of 247 the system requirements. Chin J Traumatol, 2020. 23(3): p. 168-175.

248 4. WHO, ICD-10 : international statistical classification of diseases and related health problems : tenth 249 revision, 2nd ed. 2004, World Health Organization.

250 5. Lee, K., Study on sampling method and estimaton for hospital in-depth injury survey. 2006, Korea Centers 251 for Diseases Control and Prevention.

252 6. Boo, Y., Development of National Hospital Discharge Survey Manual using Korean Uniformed Hospital 253 Discharge Data Set. 2005, KCDC, KMOHW.

254 7. KCDC, The Annual Report of Korea Hospital Discharge In-Depth Injury Survey. 2018: Cheongju-si.

255 8. Lee, K., A Study on Sampling Design and Weighting for Korea Hospital Discharge Survey. 2007, Korea 256 Centers for Diseases Control and Prevention.

257 9. Lee, K., Sampling Design of the Hospital Discharge Survey for producing Regional Statistics. 2018, Korea 258 Centers for Diseases Control and Prevention.

259 10. ICECI Coordination and Maintenance Group, I.C.a.M. International Classification of External Causes of 260 Injuries, version 1.2. 2004; Available from: https://www.whofic.nl/sites/default/files/2018261 05/ICECI\%20in\%20English.pdf.

262 11. Statistics Korea, Korean Standard Classification of Diseases and Causes of Death. 2015, Statistics Korea: 263 Daejeon.

264 12. KCDC, The Annual Report of Korea Hospital Discharge In-Depth Injury Survey. 2006, Korea Centers for 265 Diseases Control and Prevention.

266 13. KMOHW, The National Health Plan 2020. 2011, Korea Ministry of Health and Welfare: Seoul.

267 14. KMOHW, Reducing child accidents, making safe country for children. 2010, Korea Ministry of Health and 268 Welfare.

269 15. Shin, S., Collection of sample coding cases based on KCD-6 coding guidance. 2012, Statistics Korea: 270 Daejeon.

271 16. Kim, Y.J., et al., International Classification of Diseases 10th edition-based disability adjusted life years for 272 measuring of burden of specific injury. Clin Exp Emerg Med, 2016. 3(4): p. 219-238.

273 17. Lee, W., D. Lim, and H. Park, Disability adjusted life years(DALYs) for injuries using death certificates 274 and hospital discharge survey by the Korean burden of diseases study 2012. Journal of Korean medical science, 275 2016.31(Suppl 2): p. S200-S208.

276 18. Hong, J., et al., Injury prevention priority setting based on the National Injury Surveillance data in Korea. 277 Int J Inj Contr Saf Promot, 2011. 18(4): p. 285-91.

278 19. Park, H.-S. and S.-M. Kim, Medical Characteristics of the Elderly Pedestrian Inpatient in Traffic Accident. 279 Journal of Digital Convergence, 2019. 17(12): p. 345-352. 
20. Park, J.-H. and S.-H. Kang, A study on the development of predictive model for severity-adjusted length of stay in nervous system patients using machine learning. Health and Social Welfare Review, 2019. 39(1): p. 390427.

283 21. Hong, J., et al., Effect of comorbidity on length of hospital stay and in-hospital mortality among unintentionally injured patients. Accid Anal Prev, 2013. 52: p. 44-50.

285 22. Kim, H.J., et al., Pesticide poisonings in South Korea: findings from the National Hospital Discharge 286 Survey 2004-2006. Hum Exp Toxicol, 2012. 31(8): p. 751-8.

287 23. Lee, H.A., et al., The effect of contextual factors on unintentional injury hospitalization: from the Korea 288 National Hospital Discharge Survey. BMC Public Health, 2018. 18(1): p. 349-358.

289 24. Hong, S.O., et al., Main results of the Korea National Hospital Discharge In-depth Injury Survey, 2004290 2016. Epidemiol Health, 2020. 42: p. e2020044.

291 25. Park, J.M. and M.J. Kim, Epidemiologic characteristics of hospitalised patients after suicidal acts from 2922005 to 2016 in Korea: Analysis of the Korean National Hospital Discharge Survey. J Affect Disord, 2020. 275 : 293 p. $238-246$. 
1 Data Resource Profile: The Korea National Hospital Discharge In-depth Injury Survey (KNHDIS)

3 Table 1. The number of sampled hospitals, their rates of participation, and number of surveyed cases in the 4 KNHDIS

\begin{tabular}{|c|c|c|c|c|c|c|c|c|c|c|c|c|c|c|c|}
\hline \multirow{2}{*}{$\begin{array}{c}\text { Target } \\
\text { year }\end{array}$} & \multicolumn{5}{|c|}{ Number of Target population hospitals } & \multicolumn{5}{|c|}{ Number of Sample hospitals (A) } & \multicolumn{5}{|c|}{$\begin{array}{l}\text { Number of Participated hospitals (B) } \\
\text { (A/B, \%) }\end{array}$} \\
\hline & sum & $\begin{array}{l}100- \\
299\end{array}$ & $\begin{array}{c}300- \\
499\end{array}$ & $\begin{array}{l}500- \\
999\end{array}$ & $\geq 1000$ & sum & $\begin{array}{l}100- \\
299\end{array}$ & $\begin{array}{l}300- \\
499\end{array}$ & $\begin{array}{c}500- \\
999\end{array}$ & $\geq 1000$ & Sum & $\begin{array}{l}100- \\
299\end{array}$ & $\begin{array}{l}300- \\
499\end{array}$ & $\begin{array}{l}500- \\
999\end{array}$ & $\geq 1000$ \\
\hline 2004 & 512 & 334 & 84 & 84 & 10 & 150 & 70 & 27 & 43 & 10 & $\begin{array}{c}147 \\
(98.0)\end{array}$ & $\begin{array}{c}67 \\
(95.7)\end{array}$ & $\begin{array}{c}27 \\
(100.0)\end{array}$ & $\begin{array}{c}43 \\
(100.0)\end{array}$ & $\begin{array}{c}10 \\
(100.0)\end{array}$ \\
\hline 2005 & 512 & 334 & 84 & 84 & 10 & 150 & 70 & 27 & 43 & 10 & $\begin{array}{l}147 \\
(98.0)\end{array}$ & $\begin{array}{c}68 \\
(97.1)\end{array}$ & $\begin{array}{c}27 \\
(100.0)\end{array}$ & $\begin{array}{c}42 \\
(97.7)\end{array}$ & $\begin{array}{c}10 \\
(100.0)\end{array}$ \\
\hline 2006 & 512 & 334 & 84 & 84 & 10 & 150 & 70 & 27 & 43 & 10 & $\begin{array}{c}144 \\
(96.0)\end{array}$ & $\begin{array}{c}65 \\
(92.9)\end{array}$ & $\begin{array}{c}26 \\
(96.3)\end{array}$ & $\begin{array}{c}43 \\
(100.0)\end{array}$ & $\begin{array}{c}10 \\
(100.0)\end{array}$ \\
\hline 2007 & 561 & 408 & 75 & 71 & 7 & 170 & 102 & 19 & 42 & 7 & $\begin{array}{c}165 \\
(97.1)\end{array}$ & $\begin{array}{c}100 \\
(98.0)\end{array}$ & $\begin{array}{c}18 \\
(94.7)\end{array}$ & $\begin{array}{c}40 \\
(95.2)\end{array}$ & $\begin{array}{c}7 \\
(100.0)\end{array}$ \\
\hline 2008 & 561 & 408 & 75 & 71 & 7 & 170 & 102 & 19 & 42 & 7 & $\begin{array}{c}170 \\
(100.0)\end{array}$ & $\begin{array}{c}102 \\
(100.0)\end{array}$ & $\begin{array}{c}19 \\
(100.0)\end{array}$ & $\begin{array}{c}42 \\
(100.0)\end{array}$ & $\begin{array}{c}7 \\
(100.0)\end{array}$ \\
\hline 2009 & 561 & 408 & 75 & 71 & 7 & 170 & 102 & 19 & 42 & 7 & $\begin{array}{c}170 \\
(100.0)\end{array}$ & $\begin{array}{c}102 \\
(100.0)\end{array}$ & $\begin{array}{c}19 \\
(100.0)\end{array}$ & $\begin{array}{c}42 \\
(100.0)\end{array}$ & $\begin{array}{c}7 \\
(100.0)\end{array}$ \\
\hline 2010 & 561 & 408 & 75 & 69 & 9 & 170 & 103 & 18 & 40 & 9 & $\begin{array}{c}166 \\
(97.6)\end{array}$ & $\begin{array}{c}101 \\
(98.1)\end{array}$ & $\begin{array}{c}18 \\
(100.0)\end{array}$ & $\begin{array}{c}39 \\
(97.5)\end{array}$ & $\begin{array}{c}8 \\
(88.9)\end{array}$ \\
\hline 2011 & 561 & 408 & 75 & 69 & 9 & 170 & 103 & 17 & 41 & 9 & $\begin{array}{c}166 \\
(97.6)\end{array}$ & $\begin{array}{c}101 \\
(98.1)\end{array}$ & $\begin{array}{c}17 \\
(100.0)\end{array}$ & $\begin{array}{c}41 \\
(100.0)\end{array}$ & $\begin{array}{c}7 \\
(77.8)\end{array}$ \\
\hline 2012 & 561 & 408 & 75 & 69 & 9 & 170 & 103 & 17 & 41 & 9 & $\begin{array}{c}166 \\
(97.6)\end{array}$ & $\begin{array}{c}101 \\
(98.1)\end{array}$ & $\begin{array}{c}17 \\
(100.0)\end{array}$ & $\begin{array}{c}40 \\
(97.6)\end{array}$ & $\begin{array}{c}8 \\
(88.9)\end{array}$ \\
\hline 2013 & 561 & 408 & 75 & 69 & 9 & 170 & & 17 & 41 & 9 & $\begin{array}{c}164 \\
(96.5)\end{array}$ & $\begin{array}{c}99 \\
(96.1)\end{array}$ & $\begin{array}{c}17 \\
(100.0)\end{array}$ & $\begin{array}{c}41 \\
(100.0)\end{array}$ & $\begin{array}{c}7 \\
(77.8)\end{array}$ \\
\hline 2014 & 561 & 408 & 75 & 69 & 9 & 170 & 103 & 17 & 41 & 9 & $\begin{array}{c}164 \\
(96.5)\end{array}$ & $\begin{array}{c}98 \\
(95.1)\end{array}$ & $\begin{array}{c}17 \\
(100.0)\end{array}$ & $\begin{array}{c}41 \\
(100.0)\end{array}$ & $\begin{array}{c}8 \\
(88.9)\end{array}$ \\
\hline 2015 & 561 & 408 & 75 & 69 & & 170 & 102 & 18 & 41 & 9 & $\begin{array}{c}165 \\
(97.1)\end{array}$ & $\begin{array}{c}99 \\
(97.1)\end{array}$ & $\begin{array}{c}18 \\
(100.0)\end{array}$ & $\begin{array}{c}40 \\
(97.6)\end{array}$ & $\begin{array}{c}8 \\
(88.9)\end{array}$ \\
\hline 2016 & 561 & 408 & 75 & 08 & & 170 & 101 & 18 & 42 & 9 & $\begin{array}{c}161 \\
(94.7)\end{array}$ & $\begin{array}{c}95 \\
(94.1)\end{array}$ & $\begin{array}{c}17 \\
(94.4)\end{array}$ & $\begin{array}{c}41 \\
(97.6)\end{array}$ & $\begin{array}{c}8 \\
(88.9)\end{array}$ \\
\hline 2017 & 572 & 414 & 64 & & 17 & 200 & 95 & 31 & 57 & 17 & $\begin{array}{c}188 \\
(94.0)\end{array}$ & $\begin{array}{c}91 \\
(95.8)\end{array}$ & $\begin{array}{c}28 \\
(90.3)\end{array}$ & $\begin{array}{c}55 \\
(96.5)\end{array}$ & $\begin{array}{c}14 \\
(82.4)\end{array}$ \\
\hline 2018 & 572 & 414 & 64 & 77 & 17 & 200 & 95 & 31 & 57 & 17 & $\begin{array}{c}191 \\
(95.5)\end{array}$ & $\begin{array}{c}91 \\
(95.8)\end{array}$ & $\begin{array}{c}30 \\
(96.8)\end{array}$ & $\begin{array}{c}55 \\
(96.5)\end{array}$ & $\begin{array}{c}15 \\
(88.2)\end{array}$ \\
\hline
\end{tabular}




\begin{tabular}{|c|c|c|c|}
\hline Target year & $\begin{array}{r}\text { No. of hospitals } \\
\text { participated }\end{array}$ & No. of discharged cases & No. of injury related cases \\
\hline 2004 & 147 & 175,100 & 26,791 \\
\hline 2005 & 147 & 161,997 & 24,818 \\
\hline 2006 & 144 & 170,008 & 25,511 \\
\hline 2007 & 169 & 179,094 & 27,291 \\
\hline 2008 & 170 & 190,074 & 28,031 \\
\hline 2009 & 170 & 198,586 & 29,030 \\
\hline 2010 & 166 & 220,838 & 31,654 \\
\hline 2011 & 166 & 225,105 & 31,425 \\
\hline 2012 & 167 & 235,526 & 32,758 \\
\hline 2013 & 163 & 214,605 & 30,589 \\
\hline 2014 & 165 & 224,061 & 31,389 \\
\hline 2015 & 165 & 227,615 & 31,784 \\
\hline 2016 & 162 & 235,579 & 30,829 \\
\hline 2017 & 188 & 291,786 & 37,752 \\
\hline 2018 & 191 & 302,593 & 38,109 \\
\hline
\end{tabular}

9 
Table 3. The KNHDIS Data elements (as of Jun 2020)

\begin{tabular}{l|ll}
\hline Subjects & Items & Contents \\
\hline & Hospital information & $\cdot$ Hospital identification code \\
& & $\cdot$ Number of bed in hospital \\
& $\cdot$ Hospital address
\end{tabular}

The KUHDDS

\begin{tabular}{|c|c|c|}
\hline & Demographics & $\begin{array}{l}\text { - Gender } \\
\text { - Age at admission } \\
\text { - Date of birth } \\
\text { - Zip code }\end{array}$ \\
\hline & Admission information & $\begin{array}{l}\text { - Expected source of payments } \\
\text { - Admission date } \\
\text { - Discharge date } \\
\text { - Admission route (e.g. emergency, outpatient) }\end{array}$ \\
\hline & Medical information & $\begin{array}{l}\text { - Primary diagnosis KCD-10 } 10^{\text {th }}\left(\mathrm{KCD}-7^{\text {th }}\right) \text { code } \\
\text { - Additional diagnosis KCD-10 }\left(0^{\text {th }}\left(\mathrm{KCD}-7^{\text {th }}\right)\right. \\
\left.\text { code (up to } 20^{1}\right) \\
\left.\text { - External cause of injury (up to } 2^{2}\right) \\
\text { - Primary procedure ICD-9-CM } \\
\text { - Date of procedure } \\
\left.\text { - Additional procedure code (up to } 20^{1}\right) \\
\text { - Discharge method } \\
\text { - Underlying cause of death } \\
\text { - Discharge disposition (e.g. home, other } \\
\text { health care facility, expired) } \\
\text { - Treatment result (e.g. improved, ceased) }\end{array}$ \\
\hline \multicolumn{3}{|l|}{ Injured patients } \\
\hline $\begin{array}{l}\text { S00-T75, T79 } \\
(\text { ICD-10) }\end{array}$ & Injury information & $\begin{array}{l}\text { - Intent } \\
\text { - Place of occurrence } \\
\text { - Activity when injured } \\
\text { - Mechanism of injury } \\
\text { - Date of injury occurrence } \\
\text { - Nature of injury (e.g. superficial injury, open } \\
\text { wound, fracture; generated from ICD code T00- } \\
\text { 07, T20-632) } \\
\text { - Mode of transport } \\
\text { - Proximal Risk factors for intentional self- } \\
\text { harm (e.g. conflict with families, physical } \\
\text { illness, financial problem) } \\
\text { - Poisonous substance } \\
\text { - Glasgow Outcome Scale } \\
\text { - External causes of injuries (V-Y code) }\end{array}$ \\
\hline $\begin{array}{l}\text { T78, T80-T98, Y40- } \\
\text { Y98(ICD-10) }\end{array}$ & Injury information & - External causes of injuries (V-Y code) \\
\hline
\end{tabular}

12 KUHDDS: Korea Uniformed Hospital Discharge DataSet

13 KCD- $9^{\text {th }}:$ Korean Standard Classification of Diseases, KCD

14 ICD-9-CM: International Classification of Diseases, Ninth Revision, Clinical Modification

$15{ }^{1}$ surveyed up to 5 in $2004,{ }^{2}$ surveyed up to 1 in 2004 
16 Table 4. Estimated injury discharge rates ${ }^{*}, 2004-2017$

17

\begin{tabular}{|c|c|c|c|c|c|c|c|c|c|c|c|c|c|c|}
\hline & 2004 & 2005 & 2006 & 2007 & 2008 & 2009 & 2010 & 2011 & 2012 & 2013 & 2014 & 2015 & 2016 & 2017 \\
\hline Total & 9,081 & 9,477 & 9,490 & 10,091 & 10,518 & 11,131 & 11,979 & 12,488 & 13,093 & 13,184 & 13,505 & 13,800 & 14,218 & 14,199 \\
\hline Non-injuries & 7,722 & 8,007 & 7,995 & 8,551 & 8,891 & 9,464 & 10,136 & 10,663 & 11,164 & 11,222 & 11,499 & 11,732 & 12,162 & 12,042 \\
\hline Injuries & 1,359 & 1,470 & 1,495 & 1,541 & 1,628 & 1,667 & 1,843 & 1,825 & 1,929 & 1,962 & 2,006 & 2,068 & 2,056 & 2,157 \\
\hline Intent & 1,627 & 1,713 & 1,575 & 1,787 & 1,837 & 1,872 & 2,057 & 2,019 & 2,119 & 2,118 & 2,121 & 2,169 & 2,087 & 2,160 \\
\hline Non-intentional & 1,505 & 159 & 1,622 & 1,669 & 1,721 & 1,762 & 1,947 & 1,913 & 2,021 & 2,006 & 2,015 & 2,070 & 2,007 & 2,082 \\
\hline Intentional & 111 & 113 & 115 & 105 & 111 & 106 & 105 & 101 & 91 & 92 & 90 & 82 & 74 & 71 \\
\hline Unknown & 10 & 10 & 15 & 12 & 3 & 4 & 5 & 5 & 6 & 20 & 16 & 17 & 6 & 5 \\
\hline \multicolumn{15}{|l|}{ Age group } \\
\hline $0-14$ & 880 & 868 & 835 & 862 & 912 & 872 & 918 & 918 & 963 & 921 & 964 & 901 & 804 & 795 \\
\hline $15-24$ & 1,373 & 1,468 & 1,495 & 1,574 & 1,560 & 1,573 & 1,655 & 1,634 & 1,697 & 1,608 & 1,672 & 1,747 & 1,623 & 1,567 \\
\hline $25-34$ & 1,620 & 1,697 & 1,741 & 1,833 & 1,863 & 1,844 & 1,959 & 1,929 & 1,911 & 1,836 & 1,811 & 1,745 & 1,656 & 1,639 \\
\hline $35-44$ & 1,824 & 1,875 & 1,970 & 1,900 & 1,880 & 1,939 & 2,004 & 1,903 & 1,938 & 1,947 & 1,805 & 1,817 & 1,743 & 1,685 \\
\hline $45-54$ & 2,111 & 2,280 & 2,315 & 2,335 & 2,333 & 2,463 & 2,648 & 2,588 & 2,626 & 2,632 & 2,525 & 2,564 & 2,313 & 2,326 \\
\hline $55-64$ & 2,570 & 2,705 & 2,666 & 2,643 & 2,613 & 2,755 & 2,904 & 2,894 & 3,083 & 3,070 & 3,044 & 3,137 & 3,064 & 3,263 \\
\hline $65-74$ & 3,072 & 3,174 & 34,378 & 3,201 & 3,434 & 3,446 & 3,967 & 3,686 & 3,941 & 3,941 & 4,000 & 3,830 & 3,896 & 4,094 \\
\hline $75+$ & 3,958 & 4,188 & 4,451 & 4,226 & 4,641 & 4,481 & 5,242 & 5,057 & 5,644 & 5,485 & 5,786 & 6,101 & 6,272 & 6,666 \\
\hline \multicolumn{15}{|l|}{ Injury mechanism } \\
\hline Traffic accident & 669 & 690 & 714 & 746 & 743 & 745 & 77 & 734 & 771 & 729 & 731 & 738 & 670 & 660 \\
\hline Fall & 463 & 491 & 518 & 504 & 532 & 558 & 654 & 668 & 703 & 748 & 736 & 783 & 792 & 873 \\
\hline Stuck by/against & 164 & 173 & 246 & 243 & 242 & 239 & 268 & 263 & 274 & 248 & 251 & 252 & 231 & 256 \\
\hline Stabbing & 86 & 141 & 87 & 72 & 7 & 68 & 74 & 67 & 69 & 75 & 62 & 68 & 77 & 81 \\
\hline Poisoning & 47 & 47 & 61 & & 55 & 58 & 58 & 55 & 57 & 57 & 59 & 53 & 50 & 45 \\
\hline Fire/Flame ${ }^{1}$ & 35 & 323 & 35 & 46 & 54 & 61 & 59 & 52 & 56 & 56 & 67 & 58 & 51 & 31 \\
\hline Others & 163 & 152 & 90 & 124 & 134 & 143 & 172 & 180 & 189 & 205 & 215 & 217 & 216 & 214 \\
\hline
\end{tabular}

18 "Discharge rate: discharge rate per 100,000 population applied population estimate of the surveyed year.

$19{ }^{1}$ Estimates with relative standard error of less than 5. 